\title{
Identification Key to the Genera of the Tribe Gonocerini (Insecta: Hemiptera: Coreidae)
}

\author{
Emma Elizabeth Matzinger, Michael Forthman \\ University of Florida
}

Faculty mentor: Michael Forthman, Department of Entomology and Nematology

\begin{abstract}
Gonocerini is a tribe within the large, widely distributed family of insects, Coreidae Leach 1815 , and includes several pest species of agricultural significance. Additionally, species of Gonocerini can be included in comparative studies investigating the evolution of sexually-selected traits across Coreidae. However, the ability to rapidly identify genera and species of Gonocerini for inclusion in agricultural and evolutionary research has been impeded by a lack of complete identification keys and outdated partial keys. Here, we use taxonomic descriptions, type images, and distribution data to create a dichotomous key to all 11 genera of Gonocerini based primarily on morphological characteristics.
\end{abstract}

Keywords: Coreidae, taxonomic key, Gonocerini

\section{Introduction}

Frequently, researchers need to thoroughly examine countless taxonomic descriptions and type specimens (i.e., specimens on which original descriptions were based) to identify a specimen prior to scientific use. For certain groups, taxonomic descriptions can be dated as far back as the 1700 's and contain very little morphological information. Furthermore, the fact that many of these aged descriptions were written in Latin and other languages of older dialects makes them less accessible to modern researchers. An alternative - often complementary - method of identification can be provided by dichotomous taxonomic keys. Such keys contain a series of couplets which are two-way choices of contrasting statements that are often based on morphological characters. This stepwise framework helps increase ease of identification for unknown specimens by allowing both experts and non-experts to quickly exclude taxa not associated with one choice. While dichotomous keys allow users to proceed forward, they also allow them to proceed backward through the couplets if a mistake is made. (Triplehorn \& Johnson, 2005). Thus, a dichotomous key provides a rapid and convenient method of identifying a variety of organisms. 
Coreidae Leach, 1815, commonly known as leaf-footed bugs, is a family of insects within the order Hemiptera Linnaeus, 1758. This globally distributed (except Antarctica) family is comprised of 2,567 species in 436 genera and 37 tribes (CoreiodeaSF Team, 2019). These insects

can thrive in a variety of habitats and feed on a diversity of plants. Many species of Coreidae are considered pests that can have a significant impact on agriculture (Schaeffer \& Mitchell, 1983). Furthermore, species within Coreidae have become models in studies of sexual selection due to their exaggerated hind legs that are used in male-male competition to gain access to high quality territories and win mates (e.g., Procter et al., 2012; Somjee et al., 2018; Joseph et al., 2018; Emberts et al., 2018). Despite their expansive distribution, as well as economic and scientific significance, many groups of Coreidae still lack identification keys or have regional keys that do not include all currently recognized taxa. Thus, it can be difficult for entomologists to determine what genera or species of Coreidae they are handling without extensive research.

The Old World (i.e., Australia, Africa, Asia, and Europe) tribe Gonocerini (Fig. 1) is one such group of agriculturally important Coreidae (e.g., Egonyu et al., 2014; Mitchell, 2000) for which taxonomic keys of the 11 genera are lacking. Furthermore, many species have short taxonomic descriptions that are often written in Latin (Fig. 2), including the first description of a gonocerine species, Gonocerus acuteangulatus, by Goeze in 1778. In terms of modern taxonomic literature of the Gonocerini, Van Reenen's (1976) key to the genera of Gonocerini is the most comprehensive to date. However, it is incomplete and outdated due to taxonomic changes that have taken place since. For example, in recent years, new genera have been identified, such as Cletoliturus Brailovsky, 2011 and Cletoscellus Brailovsky, 2011. Furthermore, Van Reenen's key (1976) treated some genera as subgenera of others (e.g., Plinachtus Stål, 1860 was considered a subgenus of Gonocerus Berthold, 1827) or did not include other previously recognized genera (e.g., Cletomorpha Mayr, 1866 and Brunsellius Distant, 1902). Several species have also been transferred from one genus to another (e.g., Cletus decoratus Distant, 1902 was synonymized with Cletoliturus lituripennis Brailovsky, 2011), which can introduce more variability among conspecifics of a genus and render some characters less useful in delimiting genera. Lastly, certain characters used within Van Reenen's (1976) dichotomous key can be subjective between researchers, such as "eyes very bulbous" and "vertex not elevated behind the eyes or only slightly so." 


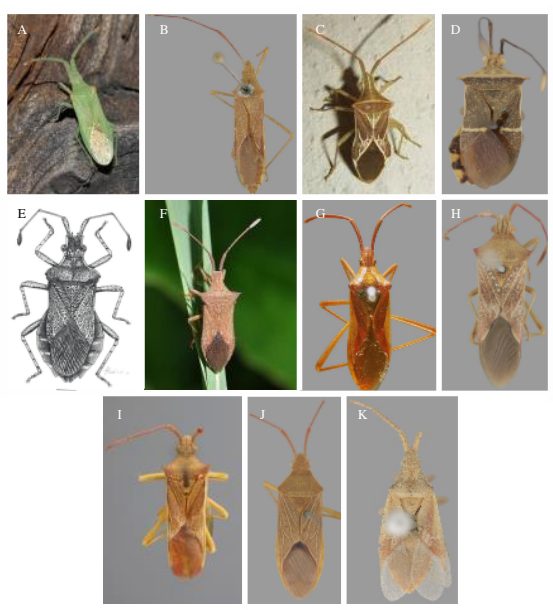

Figure 1. Digital images of representative genera of Gonocerini. (a) Brotheolus viridis (Distant, 1902), CWolfAchim Roland, https://www.inaturalist.org. (b) Brunsellius elongatus Distant, 1918 (Syntype), OTristan Bantock, http://coreoidea.speciesfile.org. (c) Cletoliturus lituripennis (Stål, 1855), CTony Benn, https://www.inaturalist.org.

(d) Cletomorpha raja Distant, 1901 (Syntype), OTristan Bantock, http://coreoidea.speciesfile.org. (e)

Cletoscellusspinijugis (Bergroth, 1905), adapted from Brailovsky (2011). (f) Cletus bipunctatus (Herrich-Schäffer, 1840), OPaul Brock, http://coreoidea.speciesfile.org, (g) Gonocerus longicornis Hsiao, 1964 (Paratype), CLaurence Livermore, http://coreoidea.speciesfile.org. (h) Junodis trilineatus (Distant, 1904) (Syntype), (OTristan Bantock, http://coreoidea.speciesfile.org. (i) Plinachtus dubius (Herrich-Schäffer, 1840) (Holotype), (CAttilio Carapezza, http://coreoidea.speciesfile.org. (j) Pseudotheraptus devastans (Distant, 1917) (Syntype), (OTristan Bantock, http://coreoidea.speciesfile.org. (k) Trallianus chennelli Distant, 1902 (Syntype), Ohttps://data.nhm.ac.uk.

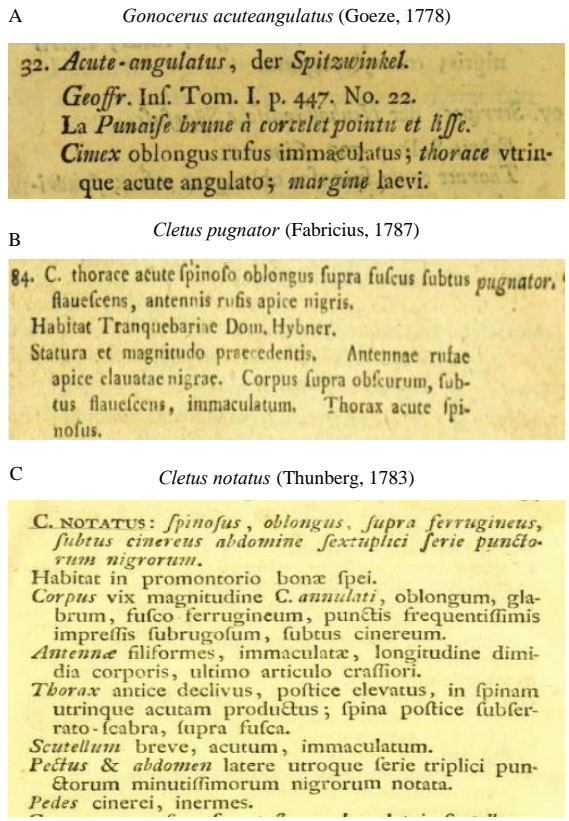

Figure 2. Examples of taxonomic descriptions written in Latin for species of Gonocerini described before 1800. (a) Goeze's (1778) original description of Gonocerus acuteangulatus. (b) Fabricius' (1787) original description of Cletus pugnator. (c) Thunberg's (1783) original description of Cletus notatus. 
Such subjective characters are not always distinctly noticeable and, thus, hinder the utility of the key if additional information or characters are not provided. Therefore, it is important for a key to be created that includes all currently recognized genera of Gonocerini based primarily on external morphological features that researchers can objectively recognize, which we address here.

\section{Materials and Methods}

We retrieved information on taxonomic literature from the Coreoidea Species File Online Catalog Version 5.0/5.0 (CoreoideaSF Team, 2019). Where available, we compared original taxonomic descriptions, re-descriptions, taxonomic notes, and previously published keys for all 11 genera of Gonocerini, as well as species descriptions when necessary. We examined this literature for external morphological characters exhibiting variation among genera to allow separation among them. In once case, the distribution of morphologically similar genera (Cletus Stål, 1860 [part] and Cletomorpha Mayr, 1866) was also used to separate them.

We also viewed images of type specimens from Coreoidea Species File and the Natural History Museum Data Portal (Scott \& Smith, 2014), where available. Type images were viewed to confirm if characters mentioned in descriptions were objectively visible. During our search for type images, we recognized three of four type specimens were incorrectly identified as Gonocerus insidiator Fabricius, 1787; these three type specimens can be confidently identified as specimens of another species in a different tribe: Haploprocta sulcicornis Fabricius, 1794. As such, we relied on the one valid type image of $G$. insidiator and the corresponding original description. When types images were not available from online repositories, we viewed non-type specimen images from iNaturalist (iNaturalist, 2019) that we could confidently assign to a genus and/or species.

We grouped genera according to morphological characteristics and distributional data that would be the basis of the dichotomous key. We used Numbers Version 5.3 and Lucid Version 3.3 to document and score characters for comparison across the genera. Below is the resulting dichotomous identification key for all genera of Gonocerini. 


\section{Dichotomous Identification Key to Genera of Gonocerini}

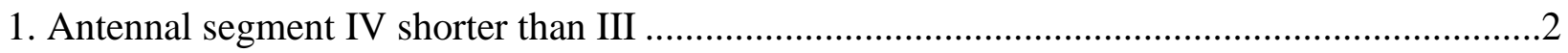

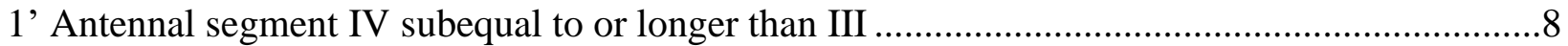

2. Apical margin of corium straight or nearly so, without a distinct narrowed apical projection

along membrane

2' Apical margin of corium sinutate, with a distinct narrowed apical projection along membrane.

3. Body very narrow and distinctly elongate (approximately five times as long as width of pronotum)..... Brunsellius Distant, 1902

3' Body not as distinctly elongate or narrow.

4. Antennal segment I shorter or as long as head; first antennal segments very short, almost contiguous with each other when extended in front of head; humeral angles not expanded laterally

Brotheolus Bergroth, 1908

4' Antennal segment I as long as or longer than head; first antennal segments more slender, not contiguous with each other when extended in front of head; humeral angles expanded laterally...5 5. Lateral margins of abdomen usually sub-parallel and not distinctly produced beyond hemelytra; posterior angles of connexiva not produced into distinct projections. Cletus Stål, 1860 (part) 5' Lateral margins of abdomen distinctly produced beyond hemelytra; posterior angles of connexiva produced into distinct projections

6. Distributed in Afrotropical, Oriental, and Australasia regions Cletomorpha Mayr, 1866

6' Distributed in Madagascar Cletoscellus Brailovsky, 2011 7. Antennal segment III laterally compressed and dorsoventrally dilated at apex; posterior margin of pronotum straight or slightly sinuate Gonocerus Berthold, 1827 7' Antennal segment III not laterally compressed and dorsoventrally dilated at apex, but cylindrical; posterior margin of pronotum medially notched, appearing distinctly sinuate Trallianus Distant, 1902

8. Lateral margins of abdomen distinctly produced beyond hemelytra...

8' Lateral margins of abdomen nearly parallel-sided and not distinctly produced beyond hemelytra....... 
9. Frons and vertex of head possessing longitudinal sulci; pale lines in an inverted T-shape spanning the head and pronotum; posterior angles of connexiva produced into distinct projections Cletoliturus Brailovsky, 2011

9' Frons and vertex of head lacking longitudinal sulci; pale lines in an inverted T-shape spanning the head and pronotum absent; posterior angles of connexiva not produced into distinct projections Cletus Stål, 1860 (part)

10. Apical margin of corium straight to sinuate with a distinct narrowed apical projection along membrane. .11

10' Apical margin of corium sinuate, lacking narrowed apical projection along membrane ........12

11. Humeral angles projected into sharp spines; if not, antennal segment I subequal to or slightly longer than head (about 1.25 times head length), apex of scutellum black ... Plinachtus Stål, 1860 11' Humeral angles blunted, not projected into sharp spines; antennal segment I distinctly longer than head (about 1.5-2 times head length); apex of scutellum not black

Pseudotheraptus Brown, 1955

12. Three narrow black longitudinal lines on head; body length approximately $17 \mathrm{~mm}$ Junodis Van Reenen 1976

12' Head without three narrow black longitudinal lines; body length less than $17 \mathrm{~mm}$ Cletus Stål, 1860 (part)

\section{References}

CoreoideaSF Team (2019). Coreoidea Species File Online Version 5.0/5.0. Retreived from http://Coreoidea.SpeciesFile.org.

Egonyu, J. P., Ekesi, S., Kabaru, J., \& Irungu, L. (2014). Biology of the coconut bug, Pseudotheraptus wayi, on French beans. Journal of Insect Science, 14(1), 44. doi:10.1093/jis/14.1.44

Emberts Z., St. Mary, C. M., Herrington, T. J., \& Miller, C. W. (2018). Males missing their sexually selected weapon have decreased fighting ability and mating success in a competitive environment. Behavioral Ecology and Sociobiology, 72, 81. doi:10.1007/s00265-018-2494-6

Fabricius, J. C. (1787). Mantissa insectorum sistens species nuper detectas adjectis synonymis, observationibus, descriptionibus, emendationibus. Tome II. Pp. 382.

Goeze, J. A. E. (1778). Entomologische Beyträge zu des Ritter Linné zwölften Ausgabe des Natursystems. Zweyter theil. Pp. 352.

iNaturalist. (n.d.). Retrieved from https://www.inaturalist.org 
Joseph, P. N., Emberts, Z., Sasson, D. A., \& Miller, C. W. (2018). Males that drop a sexually selected weapon grow larger testes. Evolution, 72(1), 113-122. doi:10.1111/evo.13387.

Mitchell, P. L. (2000). Leaf-Footed Bugs (Coreidae). In C. W. Schaefer \& A. R. Panizzi (Eds.), Heteroptera of Economic Importance (pp. 337-403). CRC Press.

Procter, D. S., Moore, A. J., \& Miller, C. W. (2012). The form of sexual selection arising from male-male competition depends on the presence of females in the social environment. Journal of Evolutionary Biology, 25(5), 803-812. doi:10.1111/j.1420-9101.2012.02485.x

Schaefer, C. W. \& Mitchell, P. L. (1983). Food plants of the Coreoidae (Hemiptera: Heteroptera). Annals of the Entomological Society of America, 76(4), 591-615. doi:10.1093/aesa/76.4.591

Scott, B. \& Smith, V. (2014). Collection Specimens. Retrieved from data.nhm.ac.uk

Somjee, U., Woods, H. A., Duell, M., \& Miller, C. W. (2018). The hidden cost of sexually selected traits: the metabolic expense of maintaining a sexually selected weapon. Proceedings of the Royal Society of London (B), 285(1891). doi:10.1098/rspb.2018.1685

Thunberg, C. P. (1783). Dissertatio entomologica novas insectorum species, sistens, cujus partem secundum.

Triplehorn, C. A., Johnson N. F. (2005). Borror and DeLong's Introduction to the Study of Insects $\left(7^{\text {th }}\right.$ ed.). Belmont, CA: Thomson Brooks/Cole.

Van Reenen, J. A. (1976). The Gonocerini of the Ethiopian Region Part I. Generic and Subgeneric Status Within the Tribe (Heteroptera: Coreidae). Annals of the Transvaal Museum, 30(4), 41-52. 